\title{
Frequent PD-L1 expression in testicular germ cell tumors
}

\author{
C D Fankhauser ${ }^{\star}, 1$, A Curioni-Fontecedro ${ }^{2}, \mathrm{~V}$ Allmann ${ }^{3}, \mathrm{~J} \mathrm{Beyer}^{2}, \mathrm{~V} \mathrm{Tischler}^{3}, \mathrm{~T} \mathrm{Sulser}^{1}, \mathrm{H} \mathrm{Moch}^{3}$ \\ and P K Bode ${ }^{3}$ \\ ${ }^{1}$ Department of Urology, University Hospital Zurich, Zurich, Switzerland; ${ }^{2}$ Department of Oncology, University Hospital Zurich, \\ Zurich, Switzerland and ${ }^{3}$ Institute of Surgical Pathology, University Hospital Zurich, Zurich, Switzerland
}

\begin{abstract}
Background: Many testicular germ cell cancers are curable despite metastatic disease, but about 10-15\% of patients fail cisplatinbased first-line treatment. Immunotherapy is considered as additional treatment approach for these patients. Inhibition of the interaction between Programmed Death Receptor 1 (PD-1) and Programmed Death Receptor Ligand 1 (PD-L1) enhances T-cell responses in vitro and mediates clinical antitumour activity. We analysed the expression of PD-L1 in testicular germ cell tumours to evaluate its potential as target for immunotherapeutic strategies.
\end{abstract}

Methods: Immunohistochemistry was performed in 479 formalin-fixed paraffin-embedded specimens using a rabbit monoclonal antibody (E1L3N). The tissue microarray consisted of 208 pure seminomas, 121 non-seminomas, 20 intratubular germ cell neoplasia unclassified (IGCNU) and 20 specimens of non-neoplastic testicular tissue.

Results: Programmed Death Receptor Ligand-1 expression was found in $73 \%$ of all seminomas and in $64 \%$ of all non-seminomas. None of 20 IGCNU and none of 20 normal tissue specimens exhibited PD-L1 expression. PD-L1 positive stromal cells were only detected in seminomas, but not in non-seminomas. The anti PD-L1 antibody showed a pre-dominantly membranous staining pattern in testicular tumour cells, as well as expression in stromal cells.

Conclusions: This frequent expression of PD-L1 in human testicular germ cell tumours suggests that patients with testicular germ cell tumours could profit from immunotherapeutic strategies using anti-PD1 and anti-PDL1 antibodies.

Testicular germ cell tumours are curable despite the presence of metastatic disease. Nevertheless, about $10-15 \%$ of patients fail cisplatin-based first-line chemotherapy and about $3-5 \%$ of all patients with testicular germ cell tumours will eventually die of their disease. Moreover, short- and long-term side effects of cisplatin-based chemotherapy make the search for new and less toxic treatment strategies worthwhile.

Programmed Death Receptor 1 (PD-1, CD279) is one of the members of the extended family of $\mathrm{T}$-cell regulators expressed on the surface of activated $\mathrm{T}$ cells, $\mathrm{B}$ cells and macrophages (Keir et al, 2008). Its ligand, Programmed Death Receptor Ligand 1 (PD-L1) (B7-H1, CD274), is expressed on tumour cells, macrophages, $\mathrm{T}$ cells and certain other tissue types (Keir et al, 2008). The interaction of these two molecules negatively regulates immune responses. Of major interest is that inhibition of the interaction between $\mathrm{PD} 1$ and PD-L1 can enhance T-cell responses in vitro and mediates clinical antitumour activity (Berger et al, 2008). PD-L1 expression in tumour specimens has been described as a predictive marker for tumour response to anti-PD1 or -PD-L1 immunotherapy in various advanced tumours, including melanoma, non-small cell lung cancer, kidney cancer, colorectal cancer, castration-resistant prostate cancer and bladder cancer (Berger et al, 2008). For example, in bladder cancer, a disease that has not seen therapeutic advances for several decades, the anti-PD-L1 antibody MPDL3280A demonstrate antitumour responses with objective response rates up to $53 \%$ in patients with PD-L1-positive tumours and 13\% in PD-L1negative tumours (Powles et al, 2014). In metastatic melanoma one-third showed objective tumour regressions to the anti PD-1 agent Nivolumab with a median response duration of 2 years (Topalian et al, 2014). The aim of this study was to investigate the expression of PD-L1 in testicular germ cell tumours. 


\section{MATERIALS AND METHODS}

Formalin-fixed paraffin-embedded tumour specimens from 329 patients diagnosed with primary testicular germ cell tumours were retrieved from the Institute of Surgical Pathology of the University Hospital Zurich, Switzerland from 1990 to 2003. The patient age ranged from 18 to 90 with a median of 33.5 years. Tumours were classified according to the 2004 WHO Classification. A tissue microarray was constructed and included a total of 208 pure seminomas and 121 non-seminomas or mixed tumours as described previously (Bode et al, 2011). In mixed germ cell tumours, each tumour component (seminomatous, embryonal carcinoma, yolk sac tumour, choriocarcinoma, teratoma) was separately punched. Briefly, the tissue microarray consisted of the following tumour components: 248 seminomas, 87 embryonal carcinomas, 48 yolk sac tumours, 46 teratomas and 10 choriocarcinomas. Furthermore, 20 samples of normal testicular tissue as well as 20 samples of intratubular germ cell neoplasia unclassified were included.

To detect the PD-L1 protein, we used the monoclonal rabbit antibody (E1L3N, Cell Signaling Technology, Inc. (CST), Danvers, MA, USA). A multi-tumour tissue microarray was used to establish a staining protocol for the PD-L1 antibody. A dilution of 1:1000 resulted in a strong and distinct membranous signal without unspecific background staining in positive controls (PD-L1positive lung cancer cases). Programmed Death Receptor Ligand1-negative lung cancer cases were used as negative controls. An experienced uropathologist (PKB) evaluated all tissue microarray spots. All results were re-evaluated by a second observer (CDF). In discrepant cases, consensus was achieved between the two observers after individual case discussion. Percentages of PD-L1-positive tumour cells and staining pattern were evaluated for each punch. Programmed Death Receptor Ligand-1 expression was recorded if a distinct membranous staining signal on the tumour cell surface or strong cytoplasmic staining within the tumour or stromal cells was observed. A 5\% cut-off value was applied for PD-L1 positivity as it has been proposed in non-small cell lung cancer (Zhang et al, 2015). To evaluate the overall tumour expression of non-seminomas, tumours with multiple components were considered PD-L1-positive if any component met these criteria.

\section{RESULTS}

Programmed Death Receptor Ligand-1 expression was found in $73 \%$ of seminomas and $64 \%$ of non-seminomas. The expression in the individual tumour components is shown in Figure 1 and summarised in Table 1 . None of the 20 precursor lesions and none of the 20 normal testicular specimens exhibited PD-L1 expression. Correlation with tumour stage showed PD-L1 expression in 53\% (pT1), 66\% (pT2) and 70\% (pT3).

In general, PD-L1 expression was found to be heterogeneous in the tumour tissue showing dispersed positive foci. Furthermore, differences between seminoma and non-seminoma were noted. The seminoma components showed a positive staining predominantly in the interface region between tumour and fibrovascular stromal septae. Frequently, some seminoma cells showed a distinct membranous staining. In the stromal septae, it was difficult to evaluate which exact cells (lymphocytes, stromal cells, endothelial cells) were positive because of the marked density of the cellular infiltrate in the stroma, but it seemed that it was mainly restricted to the lymphocytes. Most cases of non-seminoma components showed a distinct strong membranous staining of the tumour cells and only rarely expression in the tumour stroma was noted.

\section{DISCUSSION}

In this study, we observed frequent PD-L1 expression in testicular germ cell tumours, but not in their precursor lesion (intratubular
A

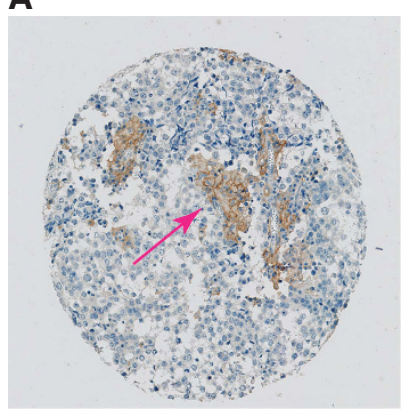

D

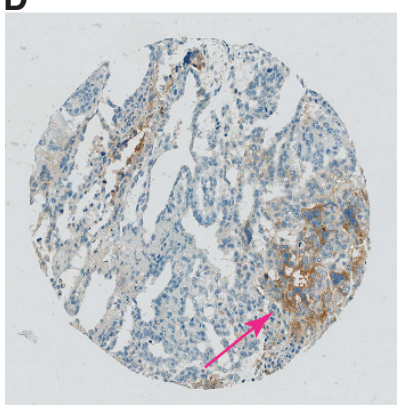

B

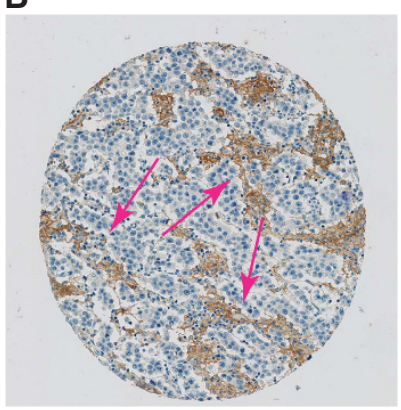

$\mathbf{E}$

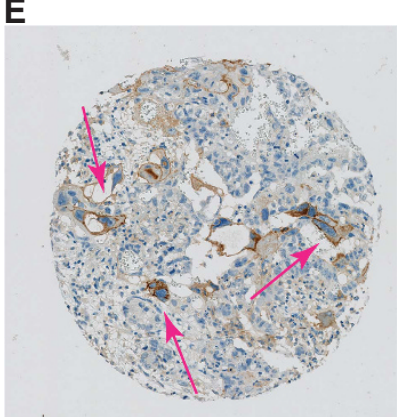

C

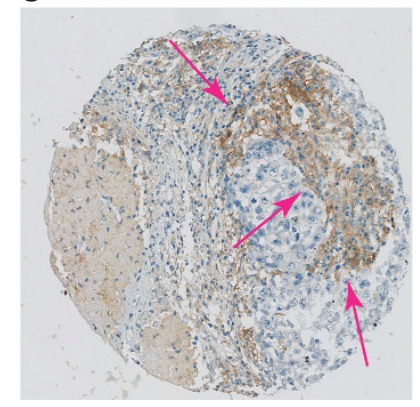

$\mathbf{F}$

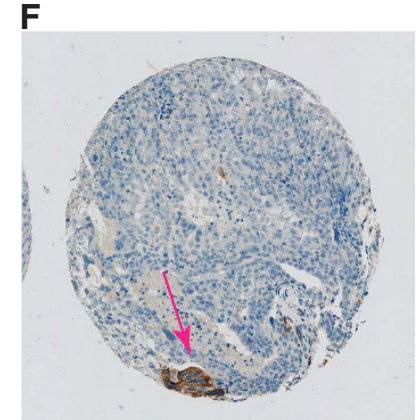

Figure 1. Programmed cell death ligand 1 (PD-L1) staining in several tumour components: Classic seminoma with distinct membrane staining in a small focus (A); Classic seminoma with typical stromal staining pattern (B); Embryonal carcinoma with typical membranous staining pattern (C); Yolk sac tumour with distinct membrane staining in a small focus (D); choriocarcinoma with strong membrane staining in dispersed tumour cells, predominantly multinucleated giant cells (E); Embryonal carcinoma with a small focus demonstrating the marked heterogeneity of PD-L1 expression (F). 
Table 1. Summary of PD-L1 expression for individual tissue types, tumour components and tumour stage

\begin{tabular}{|c|c|c|c|c|}
\hline Tissue types & Negative & Weak & Strong & $\begin{array}{c}\text { Positive } \\
\text { cases } \\
(\%)\end{array}$ \\
\hline Seminoma $(n=208)$ & 57 & 67 & 84 & $73 \%$ \\
\hline Non-seminoma $(n=121)$ & 43 & 35 & 43 & $64 \%$ \\
\hline Intratubular germ cell neoplasia & 20 & 0 & 0 & $0 \%$ \\
\hline Normal testis & 20 & 0 & 0 & $0 \%$ \\
\hline \multicolumn{5}{|c|}{ Individual tumour components } \\
\hline $\begin{array}{l}\text { Seminomatous }(n=248) \\
\text { Choriocarcinoma }(n=10) \\
\text { Yolk sac tumour }(n=48) \\
\text { Embryonal carcinoma }(n=87) \\
\text { Teratoma }(n=46)\end{array}$ & $\begin{array}{r}77 \\
2 \\
29 \\
34 \\
39\end{array}$ & $\begin{array}{r}77 \\
2 \\
12 \\
29 \\
5\end{array}$ & $\begin{array}{r}94 \\
6 \\
7 \\
24 \\
2\end{array}$ & $\begin{array}{l}69 \% \\
80 \% \\
40 \% \\
61 \% \\
13 \%\end{array}$ \\
\hline \multicolumn{5}{|l|}{ Tumour stage } \\
\hline $\begin{array}{l}\text { PT1 }(n=352) \\
\text { PT2 }(n=94) \\
\text { pT3 }(n=10)\end{array}$ & $\begin{array}{r}164 \\
32 \\
3\end{array}$ & $\begin{array}{r}83 \\
38 \\
3 \\
\end{array}$ & $\begin{array}{r}105 \\
24 \\
4\end{array}$ & $\begin{array}{l}53 \% \\
66 \% \\
70 \% \\
\end{array}$ \\
\hline
\end{tabular}

germ cell neoplasia unclassified). Importantly, normal testis was PD-L1 negative, too. The frequent expression of PD-L1 in this cohort is comparable with other genitourinary cancer like renal cell carcinoma (66\%) (Thompson et al, 2005) and bladder cancer (20\%) (Faraj et al, 2015) or non-genitourinary cancers like breast cancer (23.4\%) (Muenst et al, 2014) or colorectal cancer (36\%) (Droeser et al, 2013). In these tumours, the positive expression of PD-L1 has been described to be associated with shorter overall survival (Zhang et al, 2015). Furthermore, clinical trials suggested that the tissue expression status of PD-L1 is the most important marker to predict therapy response to PD-1 and PD-L1 immunotherapy (Berger et al, 2008). A major limitation of our study might be the lack of clinical follow-up data. Nevertheless, our accurate description of PD-L1 expression in testicular germ cell tumours forms the basis for a potential use of $\mathrm{PD}-\mathrm{L} 1$ as predictive marker in future PD-L1 immunotherapies.

We conclude that the frequent expression of PD-L1 in testicular seminomas and non-seminomas indicates that immune checkpoint blockade could be a promising new treatment approach also in testicular cancer that warrants further investigation in clinical trials.

Take home message. Frequent PD-L1 expression in testicular germ cell tumours indicates that PD-L1 immunotherapy might be a novel option in the treatment of testicular cancer.

\section{ACKNOWLEDGEMENTS}

We thank S. Dettwiler, M. Bieri, Q. Zhong and A. Wethmar (Pathology Zurich) for excellent technical assistance.

\section{CONFLICT OF INTEREST}

The authors declare no conflicts of interest.

REFERENCES

Berger R, Rotem-Yehudar R, Slama G, Landes S, Kneller A, Leiba M, Koren-Michowitz M, Shimoni A, Nagler A (2008) Phase I safety and pharmacokinetic study of CT-011, a humanized antibody interacting with PD-1, in patients with advanced hematologic malignancies. Clin Cancer Res 14(10): 3044-3051.

Bode PK, Barghorn A, Fritzsche FR, Riener MO, Kristiansen G, Knuth A, Moch H (2011) MAGEC2 is a sensitive and novel marker for seminoma: a tissue microarray analysis of 325 testicular germ cell tumors. Mod Pathol 24(6): 829-835.

Droeser RA, Hirt C, Viehl CT, Frey DM, Nebiker C, Huber X, Zlobec I, Eppenberger-Castori S, Tzankov A, Rosso R, Zuber M, Muraro MG, Amicarella F, Cremonesi E, Heberer M, Iezzi G, Lugli A, Terracciano L, Sconocchia G, Oertli D, Spagnoli GC, Tornillo L (2013) Clinical impact of programmed cell death ligand 1 expression in colorectal cancer. Eur $J$ Cancer 49(9): 2233-2242.

Faraj SF, Munari E, Guner G, Taube J, Anders R, Hicks J, Meeker A, Schoenberg M, Bivalacqua T, Drake C, Netto GJ (2015) Assessment of tumoral PD-L1 expression and intratumoral CD8 $+\mathrm{T}$ cells in urothelial carcinoma. Urology 85(3): 703.e1-6.

Keir ME, Butte MJ, Freeman GJ, Sharpe AH (2008) PD-1 and its ligands in tolerance and immunity. Annu Rev Immunol 26: 677-704.

Muenst S, Schaerli AR, Gao F, Däster S, Trella E, Droeser RA, Muraro MG, Zajac P, Zanetti R, Gillanders WE, Weber WP, Soysal SD (2014) Expression of programmed death ligand 1 (PD-L1) is associated with poor prognosis in human breast cancer. Breast Cancer Res Treat 146(1): 15-24.

Powles T, Eder JP, Fine GD, Braiteh FS, Loriot Y, Cruz C, Bellmunt J, Burris HA, Petrylak DP, Teng S-L, Shen X, Boyd Z, Hegde PS, Chen DS, Vogelzang NJ (2014) MPDL3280A (anti-PD-L1) treatment leads to clinical activity in metastatic bladder cancer. Nature 515(7528): 558-562.

Thompson RH, Gillett MD, Cheville JC, Lohse CM, Dong H, Webster WS, Chen L, Zincke H, Blute ML, Leibovich BC, Kwon ED (2005)

Costimulatory molecule $\mathrm{B} 7-\mathrm{H} 1$ in primary and metastatic clear cell renal cell carcinoma. Cancer 104(10): 2084-2091.

Topalian SL, Sznol M, McDermott DF, Kluger HM, Carvajal RD, Sharfman WH, Brahmer JR, Lawrence DP, Atkins MB, Powderly JD, Leming PD, Lipson EJ, Puzanov I, Smith DC, Taube JM, Wigginton JM, Kollia GD, Gupta A, Pardoll DM, Sosman JA, Hodi FS (2014) Survival, durable tumor remission, and long-term safety in patients with advanced melanoma receiving nivolumab. J Clin Oncol 32(10): 1020-1030.

Zhang Y, Kang S, Shen J, He J, Jiang L, Wang W, Guo Z, Peng G, Chen G, He J, Liang W (2015) Prognostic significance of programmed cell death 1 (PD-1) or PD-1 ligand 1 (PD-L1) expression in epithelial-originated cancer: a meta-analysis. Medicine (Baltimore) 94(6): e515.

This work is published under the standard license to publish agreement. After 12 months the work will become freely available and the license terms will switch to a Creative Commons AttributionNonCommercial-Share Alike 4.0 Unported License 